\title{
Antibody-Conjugated Magnetic Beads For Sperm Sexing By A Multi-Wall Carbon Nanotube Microfluidic Device
}

\section{Chalinee Phiphattanaphiphop}

Chiang Mai University

Komgrit Leksakul ( $\square$ komgrit@cmu.ac.th )

Chiang Mai University

\section{Thananut Wanta}

Chiang Mai University

\section{Trisadee Khamlor}

Chiang Mai University

\section{Rungrueang Phattanakun}

Synchrotron Light Research Institute

\section{Research Article}

Keywords: Monoclonal Antibody Conjugated, Sperm sexing, Multi-wall Carbon Nanotubes, Magnetic Beads, Microfluidic

Posted Date: June 25th, 2021

DOl: https://doi.org/10.21203/rs.3.rs-646645/v1

License: (c) (i) This work is licensed under a Creative Commons Attribution 4.0 International License. Read Full License 


\section{Abstract}

Bull production industries demand specific sexual bulls in response to different business productivity requirements. Therefore, sexual separation of sperm is essential for the livestock industry, increasing the demand for assisted reproductive technologies (ARTs). A popular sexual separation method in ART is monoclonal antibody enhancement, which does not affect the quality of the sperm and has specificity with high sexual separation accuracy. Moreover, microfluidic technique is an innovative tool for sperm separation, with increased installation efficiency and convenience but low accuracy and speed of detection. In this study, particles were separated using magnetic beads, magnetic beads on monoclonal antibodies, and sperm with the function of magnetic beads on monoclonal antibodies by controlling the microfluidic system fluid flow rate at $2 \mu \mathrm{L} / \mathrm{min}$ and releasing a $2.5-\mathrm{V}$ electric field. This microfluidic device separated $100 \%$ and $95.42 \%$ of the magnetic beads and magnetic beads on monoclonal antibodies, respectively. The sperm separation test results showed that positively charged sperm Y moved to the negative electrical fluid channel with a specially designed multi-walled carbon nanotube microfluidic device that showed an $\mathrm{X}$ - and $\mathrm{Y}$-sperm separation with a success rate of $80.12 \%$. Compared with natural pregnancy (X-and $Y$-sperm ration 50:50, 50\%), our proposed method is approximately $30.12 \%$ better.

\section{Introduction}

Bovine sperm separation technology has a significant impact on both the food and livestock industry, which leads to an increasing demand for assisted reproductive technologies (ARTs). For example, female cattle are required for the dairy industry, while males are preferred in the beef cattle industry ${ }^{[1]}$ because male cattle have a higher daily growth rate and can be fattened more easier than female cattle. Conventional sperm sexing techniques rely on centrifugation, which is known to cause oxidative stress and consequently damage cells. Moreover, the sexing of $X$ - and $Y$-spermatozoa based on differences in their chromosomal content analyzed by flow cytometry is considered to be the most reliable and effective method, in which spermatozoa of the desired sex can be obtained with greater than $90 \%$ purity ${ }^{[2,3]}$. Sperm $\mathrm{X}$ has $3.8 \%$ more DNA weight than $\mathrm{Y}$-sperm, thus providing an opportunity to use the properties of sperm with different body weights. Sexing sperm with this technique can increase the proportion of sperm with the $X$ chromosome by $90 \%[4]$. The disadvantages of using flow cytometry for sexing sperm are as follows: (1) effect of the sexually transmitted sperm during fertilization with the egg due to the pregnancy rate for $2 \times 10^{6}$ sexed sperm per inseminate was $56 \%$, whereas routine operation of a flow cytometer/cell sorter for sexing sperm results in sexing about $10 \times 10^{6} \mathrm{sperm} / \mathrm{h}$ of each sex and the typically a dose of frozen bull sperm for artificial insemination contains $20 \times 10^{6}$ sperm; (2) flow cytometers are expensive (250,000 \$ USD/device); (3) the conception rate has reduced from 50-42\%; and (4) flow cytometry requires a highly skilled technician ${ }^{[5]}$.

Recently, lab-on-a-chip (LOC) technology, in combination with microfluidics, has emerged as an innovative tool for handling small volumes of samples within a small device. Microfluidics is a field that involves the flow of liquid inside channels of micrometer size. Microfluidics can be considered both as a science, 
involving the study of the behavior of fluids in microchannels ${ }^{[6,7]}$, and technology, including manufacturing of microfluidic devices for applications, especially clinical applications ${ }^{[8-10]}$. Currently, microfluidics is utilized in many clinical applications, including biological and chemical analyses, pointof-care testing, clinical and forensic analyses, and molecular and medical diagnostics. Moreover, microfluidics has been successfully incorporated into various fields of ART, including 1) infertility diagnosis, 2) sperm selection, 3) sperm guidance, 4) oocyte analysis, 5) insemination, 6) embryo culture, 7) embryo selection, and 8) cryopreservation and verification ${ }^{[11]}$. Successful applications of microfluidic systems for sperm sorting and analysis have been discussed by Samuel et al. ${ }^{[12]}$. In addition, sperm separation methods such as fluorescence-activated cell sorting $(\mathrm{FACS})^{[13,14]}$, dielectrophoretic sorting ${ }^{[15]}$, electrophoretic sorting ${ }^{[16-18]}$, magnetic activated sperm cell sorting ${ }^{[19-21]}$, sperm sorting to utilize the difference in motility or nonmotility ${ }^{[22-27]}$, immunological markers ${ }^{[28,29]}$, electrokinetic isolation ${ }^{[30]}$, inertial separation ${ }^{[31]}$, and controlled pressure sorting ${ }^{[32]}$ are used to isolate homogeneous and concentrated cell populations from heterogeneous cell mixtures. Each sorting method has its own advantages and disadvantages. For example, the swim up method provides higher yield ${ }^{[33]}$ but low DNA integrity ${ }^{[34]}$ compared to the microfluidic technique. In terms of sorting sperm for sexual selection in fertilization, variation in electrophoretic mobility between sperm carrying $X$ or $Y$ chromosomes $(X$ and $Y$ sperms hereafter) due to a slight difference in the electrical charge of these sperms has been observed ${ }^{[35]}$. Moreover, the difference in the zeta potential of human $\mathrm{X}$ and $\mathrm{Y}$ sperms was measured using electrophoretic light scattering spectrophotometry and a laser-rotating prism. The $X$ and $Y$ sperms were then separated by free-flow electrophoresis, and their purities were determined by staining the F-body. The $\mathrm{X}$-sperm was found to have a greater net negative charge $(-20 \mathrm{mV})$ than $\mathrm{Y}$ - sperm $(-16 \mathrm{mV})^{[36]}$. Male and female mammalian sperm cells were also found to differ in sialic acid content. It was shown that motility of $X$ and $Y$ chromosome-containing sperm cells differs under a magnetic field, where the female sperm cell is faster than the male. It was shown that the electrophoretic motility differs, with mobilities equal to 1.07 and $0.41 \mu \mathrm{m} \mathrm{s}^{-1} \mathrm{~V}^{-1}$ for $X$ and $Y$ chromosomes containing spermatozoa, respectively. The difference in sialylation was further confirmed when the motility of the male female sperm cells became similar were treated with sialidase, an enzyme that hydrolyzes the negatively charged sialic acid. The changes were visible after 15 and 28 min for $Y$ and $X$ chromosome-containing sperm cells, respectively ${ }^{[37]}$. It was also observed that $X$ and $Y$ sperm cells have different zeta potentials ${ }^{[36]}$. The first evidence of this difference was seen when the $X$ chromosome-containing sperm cell had better motility than the $Y$ sperm cell under the presence of an electric field ${ }^{[38]}$. The difference in motility was explained by the fact that male and female sperm cells differ in surface charge, thus showing variable zeta potential in solution. Therefore, the difference in the surface charge was used for sexing separation.

Currently, the cattle production industry demands an increasing number of sex-specific calves. Therefore, the fabrication of microfluidic devices capable of sorting sperm for sexual selection has become a significant topic in assisted reproductive technology based on electric fields ${ }^{[39]}$. Our proposed microfluidic device design can be separated into X-/Y-sperm separation, which uses monoclonal antibody-conjugated magnetic beads. The monoclonal antibody used in this study was a monoclonal antibody specific to $\mathrm{Y}$ - 
sperm. The proposed method did not affect the quality of the desired sex sperm and showed specificity and accuracy in terms of gender separation. The $Y$ sperm captured by the monoclonal antibody is destroyed and will not affect the quality of sperm $X$, along with the use of magnetic particles and electric fields, which aids in the separation of the sex of the sperm. To study the properties of sperm $X$ and $Y$ for use in the design and construction of a microfluid system device for gender separation of cattle sperm, real-time polymerase chain reaction (PCR) was used for sperm counting. Moreover, the monoclonalantibody conjugated magnetic beads were separated on electric fields via evaluations with flow cytometry, which was found to be up to $95.42 \%$ effective. After sorting with an in-built device to test the sorting accuracy for the development of technology, the equipment can lead to future applications in the livestock industry.

\section{Materials And Methods}

A. Preparation of monoclonal antibodies conjugated with magnetic particles and sperm

\section{Control Sample}

The monoclonal antibody reaction test with flow cytometer used in the screening of sperm sex was divided into two groups: the control sample test and its negative result (control and negative control, respectively) and a monoclonal antibody $1 \mathrm{~F}$, which is an IgG antibody that binds to the $\mathrm{H}-\mathrm{Y}$ antigen located on the surface of $Y$ sperm-specific cells. The control samples were A01 and A02; A01 was the conjugate control (CC), which consisted of $50 \mu \mathrm{L}$ of FACS buffer and $50 \mu \mathrm{L}$ of bull sperm; A02 was isotype control (IC), which consisted of $1 \mu \mathrm{L}$ of ST28A antibody, $50 \mu \mathrm{L}$ of FACS buffer, and $50 \mu \mathrm{L}$ of bull sperm. However, there is no specificity for the sperm that it should not bind to the sperm. The control samples $\mathrm{A} 01$ and $\mathrm{A} 02$ are collectively referred to as negative controls (NC). They probability of the population (P1) to analyze the results of the control sample (Control), which shows the probability of the relationship between forward scatter height (FSC-H) and side scatter height (SSC-H) is represented as a dot plot format with the probability of correlation between fluorescent light intensity (FL1-H) and number. The cell (Count) in the form of a histogram, is shown in Fig. 1.

\section{Monoclonal Antibody 1F9}

Comparison with the negative control sample revealed that the monoclonal antibody 1F9 affected the bindable sperm, as mentioned above. Negative controls are unable to bind to sperm. However, the positive results obtained with the $1 \mathrm{~F} 9$ monoclonal antibody revealed that the $1 \mathrm{~F} 9$ monoclonal antibody had the ability to bind to sperm, as shown in Fig. 2. A03 is a 1F9 monoclonal antibody at a concentration of $50 \mu \mathrm{g} / \mathrm{mL}$, consisting of $100 \mu \mathrm{g} / \mathrm{mL}$ monoclonal antibody $(50 \mu \mathrm{L})$. A04 is a $1 \mathrm{~F} 9$ monoclonal antibody at a concentration of $25 \mu \mathrm{g} / \mathrm{mL}$, consisting of $50 \mu \mathrm{L}$ of $50 \mu \mathrm{g} / \mathrm{mL}$ monoclonal antibody and $50 \mu \mathrm{L}$ of cow sperm. And A06 is a monoclonal antibody $1 \mathrm{~F} 9$ at a concentration of $6.25 \mu \mathrm{g} / \mathrm{ml}$, consisting of a monoclonal antibody at a concentration of $12.5 \mu \mathrm{g} / \mathrm{ml}$ of $50 \mu \mathrm{l}$ and cow sperm of $50 \mu \mathrm{l}$. 
Sperm preparation with the 1F9 monoclonal antibody at various concentrations, it yielded different results with the sperm test and the sperm test with the ST28A antibody yielding a negative (Negative) test showing that the sperm with the 1F9 monoclonal antibody bind together and at reduced concentrations. There is a tendency to catch each other down as well. The optimum concentration for sperm binding was A04 at a concentration of $25 \mu \mathrm{g} / \mathrm{mL}$.

Preparation of monoclonal antibodies conjugated with magnetic particles

Magnetic beads (Pierce ${ }^{T M}$ NHS-Activated Magnetic Beads; Thermo Scientific ${ }^{T M}$ ) were used for the preparation of monoclonal antibodies conjugated with magnetic particles. Magnetic particles were prepared by balancing protein and magnetic particles at room temperature, and then $300 \mu \mathrm{L}$ of magnetic particles were inserted into a $1.5 \mathrm{~mL}$ microcentrifuge tube. Next, the tubes were placed in a magnetic stand, the magnetic particles were collected, and the suspended solids were disposed. Ice-cold $1 \mathrm{mM}$ hydrochloric acid $(1 \mathrm{ml})$ was added to the tube and blended for $15 \mathrm{~s}$. The tubes were placed in a magnetic stand, the magnetic particles were collected, and suspended solids were discarded. Then, $300 \mu \mathrm{L}$ of protein solution ( $1 \mathrm{mg} / \mathrm{mL}$ in coupling buffer) was added to the tube and blended for $300 \mathrm{~s}$. The tube was incubated for $2 \mathrm{~h}$ at room temperature on a rotary agitator. During the first $30 \mathrm{~min}$ of incubation, the mixture was mixed for $15 \mathrm{~s}$ every $5 \mathrm{~min}$ and then every $15 \mathrm{~s}$ every $15 \mathrm{~min}$, until the curing was complete. The tube was then placed in the magnetic stand, the magnetic particles were collected, and the suspended solids were discarded. Then, $1 \mathrm{~mL}$ of $0.1 \mathrm{M}$ glycine $(\mathrm{pH} 2)$ was added to the magnetic particles and mixed for $15 \mathrm{~s}$, and the tubes were placed in the magnetic stand. The magnetic particles were collected, and the solution of suspended solids was discarded; this process was repeated once. Thereafter, $1 \mathrm{~mL}$ of ultrapure water was added to the magnetic particles and mixed for $15 \mathrm{~s}$ in the magnetic stand. The magnetic particles were collected, while the suspended solids were discarded. A 1 $\mathrm{mL}$ of $3 \mathrm{M}$ ethanolamine $(\mathrm{pH}$ 9) was added to the magnetic particles, blended for $30 \mathrm{~s}$, and incubated for $2 \mathrm{~h}$ at room temperature on a rotary agitator, and the tubes were placed in a magnetic stand. The magnetic particles were collected and the suspensions were discarded again. Subsequently, $1 \mathrm{~mL}$ of purified water was added and mixed well, the magnetic particles were collected with a magnetic stand and suspended solids were discarded before adding $1 \mathrm{~mL}$ of coupling buffer (50 M borate, $\mathrm{pH} 8.5$ ) with $0.05 \%$ sodium azide and mixed well. The magnetic particles were collected with a magnetic stand, discarding the suspension, and the process was repeated two more times, with $300 \mu \mathrm{L}$ of coupling buffer and $0.05 \%$ sodium azide, mixed well, and stored at $4^{\circ} \mathrm{C}$ until use. Finally, monoclonal antibodies conjugated with magnetic particles were rechecked by flow cytometry, as shown in Fig. 3.

From the flow cytometry test of the A07 sample, the test result was negative. The result of the A07 sample was used as a negative control sample for comparison with the A08 sample. The A08 sample is a GaM-FITC-dyed magnetic bead on a monoclonal antibody, as shown in Fig. 4. From the flow cytometry test of the A08 sample, the test was positive when comparing the negative result from the A07 sample, the magnetic bead and the monoclonal antibody matched each other. The compatibility was $94.54 \%$, as shown in Table 1. 
Table 1. Physical Characteristics of Magnetic Particle Beads on Monoclonal Antibody Stained with GaMFITC (Plot 2)

\begin{tabular}{|lllllll|}
\hline $\begin{array}{l}\text { Plot 2: A08 Beads+anti- } \\
\text { sperm+ GaM-FITC }\end{array}$ & Count & $\begin{array}{l}\text { Events/ } \\
\mathbf{\mu L}\end{array}$ & $\begin{array}{l}\text { \% of This } \\
\text { Plot }\end{array}$ & \% of All & $\begin{array}{l}\text { Mean } \\
\text { FL1-H }\end{array}$ & $\begin{array}{l}\text { CV FL1- } \\
\text { All }\end{array}$ \\
\hline 11,931 & 5966 & $100.00 \%$ & $100.00 \%$ & $25,833.83$ & $177.21 \%$ \\
\hline V1-L (1.0/528.0) & 652 & 326 & $5.46 \%$ & $5.46 \%$ & 144.73 & $78.39 \%$ \\
\hline V1-R (528.0/16,777,215.0) & 11,279 & 5640 & $94.54 \%$ & $94.54 \%$ & $27,318.83$ & $170.78 \%$ \\
\hline
\end{tabular}

Monoclonal antibodies conjugated with magnetic particles and sperm

The Holstein Friesian bull semen samples used in this study were purchased from the Dairy Farming Promotion Organization of Thailand. A single straw of bull semen sample containing $30 \times 10^{6}$ spermatozoa preserved in liquid nitrogen was thawed in a water bath at $37^{\circ} \mathrm{C}$ for $40 \mathrm{~s}$. Thereafter, the sample was placed into a $1.5 \mathrm{~mL}$ micro centrifuge tube and stored in a chamber at a temperature of $37^{\circ} \mathrm{C}$. Live sperm with mortality greater than $70 \%$ was used. One microliter of warm PBS extender at $37^{\circ} \mathrm{C}$ was added to remove the egg yolk extender from the spermatozoa. Subsequently, a tube of sperm sample was centrifuged at $12,000 \mathrm{rpm}$ for $10 \mathrm{~s}$ thrice, and the supernatant was discarded to collect the sperm pellet. Turk's solution was mixed with sperm at a ratio of 1:10. Then, the sperm was blocked with $A B$ serum (FC Receptor) for 30 min. Finally, a total of six sperm tubes were prepared: Tube 1, monoclonal antibody $100 \mu \mathrm{g} / \mathrm{mL}, 50 \mu \mathrm{L}$ volume and $50 \mu \mathrm{L}$ sperm. Tube $2,50 \mu \mathrm{g} / \mathrm{mL}$ monoclonal antibody, $50 \mu \mathrm{L}$ volume and $50 \mu \mathrm{L}$ sperm. Tube $3,25 \mu \mathrm{g} / \mathrm{mL}$ monoclonal antibody, $50 \mu \mathrm{L}$, and $50 \mu \mathrm{L}$ sperm. Tube 4, 12.5 $\mu \mathrm{g} / \mathrm{mL}$ monoclonal antibody, $50 \mu \mathrm{L}$ volume, and $50 \mu \mathrm{L}$ sperm. Tube $5,1 \mu \mathrm{L}$ ST28A antibody, $50 \mu \mathrm{L} \mathrm{FACS}$ buffer, and $50 \mu \mathrm{L}$ sperm. Tube 6, $50 \mu \mathrm{L}$ FACS Buffer, and $50 \mu \mathrm{L}$ sperm.

\section{B. Microfluidic Device Fabrication}

The design of the microfluidic chip, which mainly consists of a $Y$ channel cell microfluidic channel (Fig. $5 a)$ with a pair of electrodes positioned at the separation regions is shown in Fig. 5b. The microfluidic chip was designed using a layout editor program. The dimensions of the microfluidic chip were $6,000 \mu \mathrm{m}$ $\times 150 \mu \mathrm{m}$, and it was $50 \mu \mathrm{m}$ in thickness. A pair of Ti/Au electrodes was deposited with dimensions of $5,000 \times 500 \mu \mathrm{m}$ and a thickness of $100 \mathrm{~nm}$.

The microfluidic chip was placed on a glass wafer using UV and soft lithography processes. Figure 6 illustrates the microfabrication process. To create a microelectrode, the UV patterned electrode deposition was fabricated by spin-coating the AZ P1512 photoresist on the substrate and exposed to UV to develop the patterned electrode. Thin files of Ti/Au layers $(50 / 50 \mathrm{~nm}$ ) were deposited on the glass substrate by thermal evaporation. Then, left off by acetone was employed to achieve the final electrodes (Fig. 6a). To create a microchannel, the SU-8 photoresist (SU-8 drysheet $50 \mu \mathrm{m}$ ) for the microstructure was laminatecoated and patterned. UV exposure was performed on SU-8 at $60 \mathrm{~s}$ to achieve a thickness of $50 \mu \mathrm{m}$ of SU8. The entrapping structure was designed to be wider than the space between the two sidewall electrodes 
to create the detection signal in the chamber. To provide the inlet and outlet flow of fluidic interconnections, a replicated polydimethylsiloxane sylgard 184 (PDMS-184) with multi-wall carbon nanotubes was used as the master mold replication (Fig. 6b). Finally, PDMS with multi-wall carbon nanotubes, which have a microchannel-patterned underneath, were bonded by the plasma $\mathrm{O}_{2}$ method on a pair of Ti/Au electrodes (Fig. 6c).

To set up the electrical base on the microelectrode connection, the microdevice was attached to the print circuit board and connected by using the wire bonding method in the experimentation.

\section{Results}

\section{Testing the magnetic particle beads}

The magnetic particle beads were separated using a microfluidic chip. The properties of the magnetic beads were attributed to the positively charged N-hydroxysuccinimide (NHS) functional groups on the blocked magnetic bead surface. Using electrophoresis, the magnetic beads were tested by separating the beads on a microfluidic device using the principle of the charge on the surface of magnetic beads. Electrophoresis is a laboratory technique used extensively to separate DNA, RNA, or protein molecules based on their size and electrical charge. Therefore, the optimized condition for the separation of charged beads, as understood from Phiphattanaphiphop's research, included a microfluidic device with a $150 \mu \mathrm{m}$ microchannel and $100 \mu \mathrm{m}$ electrode distance and showed the highest performance of $87.07 \%$ validation ( $95 \%$ confidence level) for the separation of negatively charged $\mathrm{TiO}_{2}$-coated PS beads ${ }^{[18]}$. An optimally designed structure used previously for the separation of the microfluidic beads was used to test the magnetic particle beads. The magnetic particle beads were prepared by controlling the sample flow rate at $2 \mu \mathrm{L} / \mathrm{min}$. This microfluidic system device was able to separate magnetic particle beads (Fig. 7).

Moreover, magnetic particle beads were tested on the MWCNT-microfluidic chip. It was processed into a pelletized form for use in the microelectrode area, as shown in Fig. 8. The magnetic particle beads were controlled using a BS-8000 syringe pump (Braintree Scientific, Inc., Braintree, MA, USA) at a flow rate at 2 $\mu \mathrm{l} / \mathrm{min}$. It was found that this MWCNT-microfluidic system device was able to separate magnetic particle beads at $100 \%$ success as shows in Table 2 .

Table 2

Separation of sample magnetic particle beads with microfluidic chip and MWCNT-microfluidic chip

\begin{tabular}{|lll|}
\hline Test sample & $\begin{array}{l}\text { Sorting capacity (\%) } \\
\text { Microfluidic chip }\end{array}$ & $\begin{array}{l}\text { Sorting capacity (\%) } \\
\text { MCNT-Microfluidic chip }\end{array}$ \\
\hline Magnetic particle & 100 & 100 \\
\hline
\end{tabular}

\section{Testing the monoclonal antibodies conjugated with magnetic particles}


In additional the monoclonal antibody conjugated with magnetic particles was added to achieve a better effect of separating in a microfluidic chip. From the experiment test for separating various particles, including magnetic particles on a monoclonal antibody with the function of monoclonal antibodies and magnetic particles by controlling the sample flow rate at $2 \mu \mathrm{l} / \mathrm{min}$. It was found that this microfluidic system device was able to separate magnetic particles on a monoclonal antibody. The results were achieved at $95.42 \%$ as shown in the Fig. 9 . And when it was used to sort the monoclonal antibody conjugated with magnetic particles in MWCNT-microfluidic chip, it was found that the results were in line with the theory, that is, the results of separating the monoclonal antibody conjugated with magnetic particles with higher positive charge at $98.84 \%$ as shows in Table 3.

Table 3

Separation of the sample magnetic particles on monoclonal antibody in microstructure flow channel with microfluidic and MWCNT-microfluidic chip.

\begin{tabular}{|lll|}
\hline Test sample & $\begin{array}{l}\text { Sorting capacity (\%) } \\
\text { Microfluidic chip }\end{array}$ & $\begin{array}{l}\text { Sorting capacity (\%) } \\
\text { MCNT-Microfluidic chip }\end{array}$ \\
\hline Magnetic Particles on Monoclonal Antibody & 95.42 & 98.84 \\
\hline
\end{tabular}

Testing Sperm and sperm with monoclonal antibodies conjugated magnetic particle beads in microfluidic chip

Sperm and sperm with monoclonal antibody-conjugated magnetic particle beads were added to achieve better separation on a microfluidic chip compared with that on a MCNT-microfluidic chip. The sperm with monoclonal antibodies conjugated with magnetic particles in a microchannel in a microfluidic system device and microelectrode was tested. The particle flow was observed in the microscopic flow channel. The particle inflow rate was controlled at $2 \mu \mathrm{L} / \mathrm{min}$, and the electric fields were discharged at $2.5 \mathrm{~V}$ for the microfluidic chip. The results were achieved at $61.11 \%$ and $80.12 \%$ for sperm conjugated monoclonal antibodies and magnetic particle beads, respectively, as shown in the microfluidic chip and MCNTmicrofluidic chip, respectively in Fig. 10. The results of the sperm in combination with monoclonal antibodies conjugated with magnetic particles show better efficacy compared with those by non-antibody coadministration with beads, as shown in Table 4.

Table 4

Separation of the sample magnetic particle beads on a monoclonal antibody and sperm in microstructure flow channel with microfluidic and MCNT-Microfluidic chip

\begin{tabular}{|lll|}
\hline Test sample & $\begin{array}{l}\text { Sorting capacity (\%) } \\
\text { Microfluidic chip }\end{array}$ & $\begin{array}{l}\text { Sorting capacity (\%) } \\
\text { MCNT-Microfluidic chip }\end{array}$ \\
\hline Antibody + Magnetic beads + Sperm & 61.11 & 80.12 \\
\hline Sperm $^{18}$ & $53.99 \pm 1.46$ & $74.62 \pm 1,09$ \\
\hline
\end{tabular}

\section{Discussion}


The micro-fluid system and micro-electrodes were created from the experiments for separating particles with the device. The particle flow was observed in the microscopic flow channel. By controlling the inflow rate of particles and emitting electric fields of various sizes, the following results were obtained.

\section{The magnetic particles beads in Microfluidic system}

The magnetic particle separation experiment by controlling the inflow rate of magnetic particles at 2 $\mu \mathrm{L} / \mathrm{min}$ and emitting a $1 \mathrm{~V}$ electric field found that the magnetic particles were released into the microstructure flow channel in the microfluidic chip. It flows through the main flow channel and into the negative-ion flow channel. The magnetic particles released into the microstructure flow channel were positively charged at the north poles. Therefore, the magnetic particles flow out of the negative-ion flow channel rather than the positive charge flow channel. According to the theory of electricity and magnetism, the same polarity or charge repel each other. This shows that the generated microfluid system device can separate magnetic particles with a success rate of $100 \%$ on both the microfluidic chip and MCNT-microfluidic chip, as understood from using flow cytometry.

\section{The monoclonal antibodies conjugated with magnetic particle beads}

The monoclonal antibody, 1F9, was conjugated with magnetic particle beads. Monoclonal antibody 1F9 will only react with $\mathrm{Y}$ sperm; in other words, monoclonal antibody1F9 will bind to sperm Y. Positively charged magnetic particle beads conjugated with monoclonal antibodies $1 \mathrm{~F} 9$ are attracted by the generated microfluidic device structure. By generating a magnetization electric field at $2.5 \mathrm{~V}$, the device was found to be able to selectively screen antibody-coated magnetic beads with a success rate of $95.42 \%$ in microfluidic chip and $98.84 \%$ in the MCNT-Microfluidic chip. The analyzes were conducted using flow cytometry machines. Therefore, the magnetic particles flow out of the negative ion flow channel rather than the positive charge flow channel. The monoclonal antibodies with magnetic particles had little effect on magnetization, which could adjust the size of the electric field from 1 to $2.5 \mathrm{~V}$. The magnitude of the electric field at $2.5 \mathrm{~V}$ was the maximum value of the electric field. It can be used without forming air bubbles or adversely affecting the microfluidic systems. This shows that the generated microfluidic system device can isolate magnetic particle beads on a monoclonal antibody.

\section{Sperm and sperm with monoclonal antibodies conjugated magnetic particle beads}

Sperm sexing experiments combined with magnetic particle beads function on a monoclonal antibody by controlling the inflow rate of the sample at $2 \mu \mathrm{L} / \mathrm{min}$ and releasing a $2.5-\mathrm{V}$ electric field found that the sperms working with magnetic particles on the monoclonal antibody were released into the micro-

microstructure flow channel. It flows through the main flow channel and separately to both exits-the positive charge flow channel and the negative charge flow channel. In order to check for clear results, the accuracy was checked using real-time PCR.

The analysis of the sperm screened with the microfluidic system using real-time PCR technique was used to determine the DNA content of the Y-sperm in the sample. To investigate the accuracy of sperm gender 
separation, samples that flowed through the anion channel containing the Y-sperm DNA load were collected from the outlet of the anion flow channel, which was $53.99 \%$ non-antibody coadministration with beads in the microfluidic chip. The results of the test for sperm without monoclonal antibodies at the magnetic bead conjugate in the MCNT-microfluidic chip were $74.62 \%{ }^{[18]}$. The test results of sperm with monoclonal antibodies at the magnetic bead conjugate were isolated at $61.11 \%$ of the microfluidic chip and $80.12 \%$ of the MCNT-microfluidic chip. It can be seen that the monoclonal antibodies with the magnetic bead conjugate will result in superior sperm separation in both the microfluidic and MCNTmicrofluidic chip. Based on the principle of separation of using a monoclonal antibody and magnetic beads to increase the screening capacity of sperm using an electric field, the result supports the hypothesis that an improved non-monoclonal antibody at the magnetic bead conjugate is achieved with a success rate of up to $80 \%$. However, the magnetic bead conjugate monoclonal antibody method is used for specific sample selection. Specifically tailored to specific sex needs, samples using conjugated antibodies were not available, and the sample used for this finding was sperm. $X$, which is $20 \%$ of the $Y$ sperm in size, with the ratio of $X$-sperms being greater than $Y$-sperms, resulting in an increased success rate in obtaining sex $X$-sperm.

\section{Conclusions}

In this study, magnetic particle beads were designed to conjugate monoclonal antibody-specific Y-sperm. The separation was performed using a microfluidic system, designed using multi-walled carbon nanotubes for separation by sexing $X$ - and $Y$-sperms. Separation was performed based on the assumption that the $X$ and $Y$ sperms had different electrical charges on the surface. The microfluidic devices used in this research were designed based on the optimal values from previous research in which a microfluidic device with a 150- $\mu \mathrm{m}$ microchannel and $100-\mu \mathrm{m}$ electrode distance were used, and the structure was constructed from MCNT-microfluidic chip ${ }^{[18]}$. Based on the sorting test results in which monoclonal antibodies were conjugatedwith the magnetic particle beads, the device could sort the magnetic particle beads, monoclonal antibody-conjugated magnetic particle beads, and spermconjugated monoclonal antibodies with success rates of $100 \%, 95.42 \%$, and $61.11 \%$, respectively, in the microfluidic structure. The MCNT-microfluidic chip successfully sorted magnetic particle beads, monoclonal antibody-conjugated magnetic particle beads, and sperm-conjugated monoclonal antibodies with magnetic particles, with success rates of $100 \%, 98.84 \%$, and $80.12 \%$, respectively. The original device sorted the antibody-free sperm in the microfluidic device at only $53.99 \%$ success rute and in the MCNTmicrofluidic chip at $74.62 \%$ success rate; therefore, success in sperm sorting when the monoclonal antibody is applied to the magnetic particle beads has a better effect than without it, but there are limitations in the specificity of the monoclonal antibody application because it can result in only one gender segregation. Moreover, it can be seen that the best sperm-sexing structures are those created using multi-wall carbon nanotubes in microfluidic devices. Sperm separation was performed using an electric field separation principle and a microfluidic structure design using multi-wall carbon nanotubes to optimize the separation and magnetic bead conductivity and achieve better rejection. This separation result supports the hypothesis that $\mathrm{X}$ - and $\mathrm{Y}$-sperms have different electrical charges on their surfaces. 


\section{Declarations}

\section{Acknowledgment}

The authors express their sincere thanks to the Thailand Science Research and Innovation (TSRI) provided financial support via Chiang Mai University (CMU) for budgeting year 2021. The Synchrotron Light Research Institute furnished the experimental apparatus and instruments.

\section{Contribution}

C.P., K.L. and T.W. are the principle investigator and wrote the main manuscript. T.K. and R.P. is the facility supporter and anlysis advisor.

\section{Corresponding author}

Correspondence to Komgrit Leksakul.

\section{Corresponding author Ethics declarations}

The authors declare no competing interests.

\section{References}

1. Seidel Jr, G. E. Overview of sexing sperm. Theriogenology $68,443-446$ (2007). 10.1016/j.theriogenology.2007.04.005, Pubmed:17512976.1.

2. Morrell, J. M., Keeler, K. D., Noakes, D. E., Mackenzie, N. M. \& Dresser, D. W. Sexing of sperm by flow cytometry. Vet. Rec. 122, 322-324 (1988). 10.1136/vr.122.14.322, Pubmed:3164152.

3. Garner, D. L. \& Seidel Jr., G. E. Jr. Past, present and future perspectives on sexing sperm. Can. J. Anim. Sci. 83, 375-384 (2003). 10.4141/A03-022.

4. Zhang, B., Yin, T. L. \& Yang, J. A novel microfluidic device for selecting human sperm to increase the proportion of morphologically normal, motile sperm with uncompromised DNA integrity. Anal. Methods 7, 5981-5988 (2015). 10.1039/C5AY00905G.

5. Zhang, H. et al. Selection of viable human spermatozoa with low levels of DNA fragmentation from an immotile population using density gradient centrifugation and magnetic-activated cell sorting. Andrologia 50, e12821 (2018). 10.1111/and.12821, Pubmed:28466479.

6. Chiriacò, M. S. et al. Fabrication of interconnected multilevel channels in a monolithic SU-8 structure using a LOR sacrificial layer. Microelectron. Eng. 164, 30-35 (2016). 10.1016/j.mee.2016.07.006.

7. Primiceri, E. et al. Key enabling technologies for Point-Of-Care Diagnostics. Sensors 18 (2018). 10.3390/s18113607, Pubmed:30355989.

8. Kashaninejad, N., Shiddiky, M. J. A. \& Nguyen, N.-T. Advances in microfluidics-based assisted reproductive technology: From sperm sorter to reproductive system-on-a-chip. Adv. Biosys. 2, Art. no. 1700197 (2018). 10.1002/adbi.201700197. 
9. Zheng, Y., Nguyen, J., Wei, Y. \& Sun, Y. Recent advances in microfluidic techniques for single-cell biophysical characterization. Lab Chip 13, 2464-2483 (2013). 10.1039/C3LC50355K, Pubmed:23681312.

10. Seger, U., Gawad, S., Johann, R., Bertsch, A. \& Renaud, P. Cell immersion and cell dipping in microfluidic devices. Lab Chip 4, 148-151 (2004). 10.1039/B311210A, Pubmed:15052356.

11. Kashaninejad, N., Shiddiky, M. J. A. \& Nguyen, N.-T. Advances in microfluidics-based assisted reproductive technology: From sperm sorter to reproductive system-on-a-chip. Adv. Biosys. 2 (2018). 10.1002/adbi.201700197.

12. Samuel, R. et al. Microfluidic - Based sperm sorting \& analysis for treatment of male infertility. Transl. Androl. Urol. 7, S336-S347 (2018). 10.21037/tau.2018.05.08, Pubmed:30159240.

13. Bonner, W. A., Hulett, H. R., Sweet, R. G. \& Herzenberg, L. A. Fluorescence activated cell sorting. Rev. Sci. Instrum. 43, 404-409 (1972). 10.1063/1.1685647, Pubmed:5013444.

14. Johnson, L. A. et al. Gender preselection in humans Flow cytometric separation of $X$ and $Y$ spermatozoa for the prevention of X-linked diseases. Hum. Reprod. 8, 1733-1739 (1993). 10.1093/oxfordjournals.humrep.a137925, Pubmed:8300839.

15. Kang, Y., Li, D., Kalams, S. A. \& Eid, J. E. DC-dielectrophoretic separation of biological cells by size. Biomed. Microdevices 10, 243-249 (2008). 10.1007/s10544-007-9130-y, Pubmed:17899384.

16. Fleming, S. \& Aitken, R. J. Electrophoretic Sperm Separation 423-429 (Springer, New York, 2011).

17. Solomon, D. H., Caulfield, M. J. \& Purss, H. K. POLYMERIC MEMBRANES and USES THEREOF, Vol (United States, 2005).

18. Phiphatanaphiphop, C. et al. Multiwalled Carbon nanotubes in Microfluidic chip for the Separation of X- and Y-Sperm based on a Photolithography Technique. IEEE. J. Microelectromech. Syst., Page(s): $1264-1277$ (2020).

19. Rappa, K. L. et al. Sperm processing for advanced reproductive technologies: Where are we today? Biotechnol. Adv. 34, 578-587 (2016). 10.1016/j.biotechadv.2016.01.007, Pubmed:26845061.

20. Grunewald, S. et al. Molecular glass wool filtration as a new tool for sperm preparation. Hum. Reprod. 22, 1405-1412 (2007). 10.1093/humrep/dem015, Pubmed:17337472.

21. Said, T. M. et al. Utility of magnetic cell separation as a molecular sperm preparation technique. $J$ Andro/ 29, 134-142 (2008). 10.2164/jandrol.107.003632, Pubmed:18077822.

22. Phiphattanaphiphop, C., Leksakul, K., Phatthanakun, R. \& Khamlor, T. A novel microfluidic chip-based sperm-sorting device constructed using design of experiment method. Sci. Rep. 10, article number: 17143 (2020). 10.1038/s41598-020-73841-3, Pubmed:33051512.

23. Zhang, X. et al. Lensless imaging for simultaneous microfluidic sperm monitoring and sorting. Lab Chip 11, 2535-2540 (2011). 10.1039/c1lc20236g, Pubmed:21677993.

24. Zhang, Y. et al. Generation of gradients on a microfluidic device: Toward a high-throughput investigation of spermatozoa chemotaxis. PLOS ONE 10, e0142555 (2015). 10.1371/journal.pone.0142555, Pubmed:26555941. 
25. Ul, H. A. et al. Anim. Reprod. Sci. 182, 69 (2017).

26. Beernink, F. J., Dmowski, W. P. \& Ericsson, R. J.. Sex preselection through albumin separation of sperm. Fertil. Steril. 59, 382-386 (1993). 10.1016/S0015-0282(16)55681-7, Pubmed:8425635.

27. Ericsson, R. J., Langevin, C. N. \& Nishino, M.. Isolation of fractions rich in human Y sperm. Nature 246, 421-424 (1973). 10.1038/246421a0, Pubmed:4587152.

28. Domínguez, E. et al. Sci. 65, 123 (2018).

29. Hashimoto, H., Eto, T., Suemizu, H. \& Ito, M.. Application of a New Convenience Gender Sorting Method for Mouse Spermatozoa to Mouse Reproductive Engineering Technology. J. Vet. Med. Sci. 75, 231-235 (2013). 10.1292/jvms.12-0303.

30. Xuan, X. \& Li, D. Focused electrophoretic motion and selected electrokinetic dispensing of particles and cells in cross-microchannels. Electrophoresis 26, 3552-3560 (2005). 10.1002/elps.200500298, Pubmed:16110466.

31. Di Carlo, D. D., Irimia, D., Tompkins, R. G. \& Toner, M. Continuous inertial focusing, ordering, and separation of particles in microchannels. Proc. Natl Acad. Sci. U. S. A. 104, 18892-18897 (2007). 10.1073/pnas.0704958104, Pubmed:18025477.

32. Seo, D.-b., Agca, Y., Feng, Z. C. \& Critser, J. K. Development of sorting, aligning, and orienting motile sperm using microfluidic device operated by hydrostatic pressure. Microfluid. Nanofluid. 3, 561-570 (2007). 10.1007/s10404-006-0142-3.

33. Henkel, R. R. \& Schill, W.-B. Reprod. Biol. Endocrinol. 1, 108 (2003). 10.1186/1477-7827-1-108.

34. Aitken, R. J. \& Clarkson, J. S.. Significance of reactive oxygen species and antioxidants in defining the efficacy of sperm preparation techniques. J. Androl. 9, 367-376 (1988). 10.1002/j.19394640.1988.tb01067.x, Pubmed:3215823.

35. Engelmann, U., Krassnigg, F., Schatz, H. \& Schill, W. B. Separation of human X and Y spermatozoa by free-flow electrophoresis. Gamete Res. 19, 151-160 (1988). 10.1002/mrd.1120190205, Pubmed:3209178.

36. Ishijima, S. A., Okuno, M. \& Mohri, H.. Zeta potential of human X-and Y-bearing sperm. Int. J. Androl. 14, 340-347 (1991). 10.1111/j.1365-2605.1991.tb01102.x, Pubmed:1794918.

37. Kaneko, S., Oshio, S., Kobayashi, T., lizuka, R. \& Mohri, H.. Human X- and Y-bearing sperm differ in cell surface sialic acid content. Biochem. Biophys. Res. Commun. 124, 950-955 (1984). 10.1016/0006291x(84)91050-7, Pubmed:6542364.

38. Kaneko, S. et al.. Separation of human X-and Y-bearing sperm using free-flow electrophoresis. Proc. Jpn. Acad. Ser. B 59, 276-279 (1983). 10.2183/pjab.59.276.

39. Rao, L. et al. A microfluidic electrostatic separator based on pre-charged droplets. Sens. Actuators $B$ 210, 328-335 (2015). 10.1016/j.snb.2014.12.057.

\section{Figures}



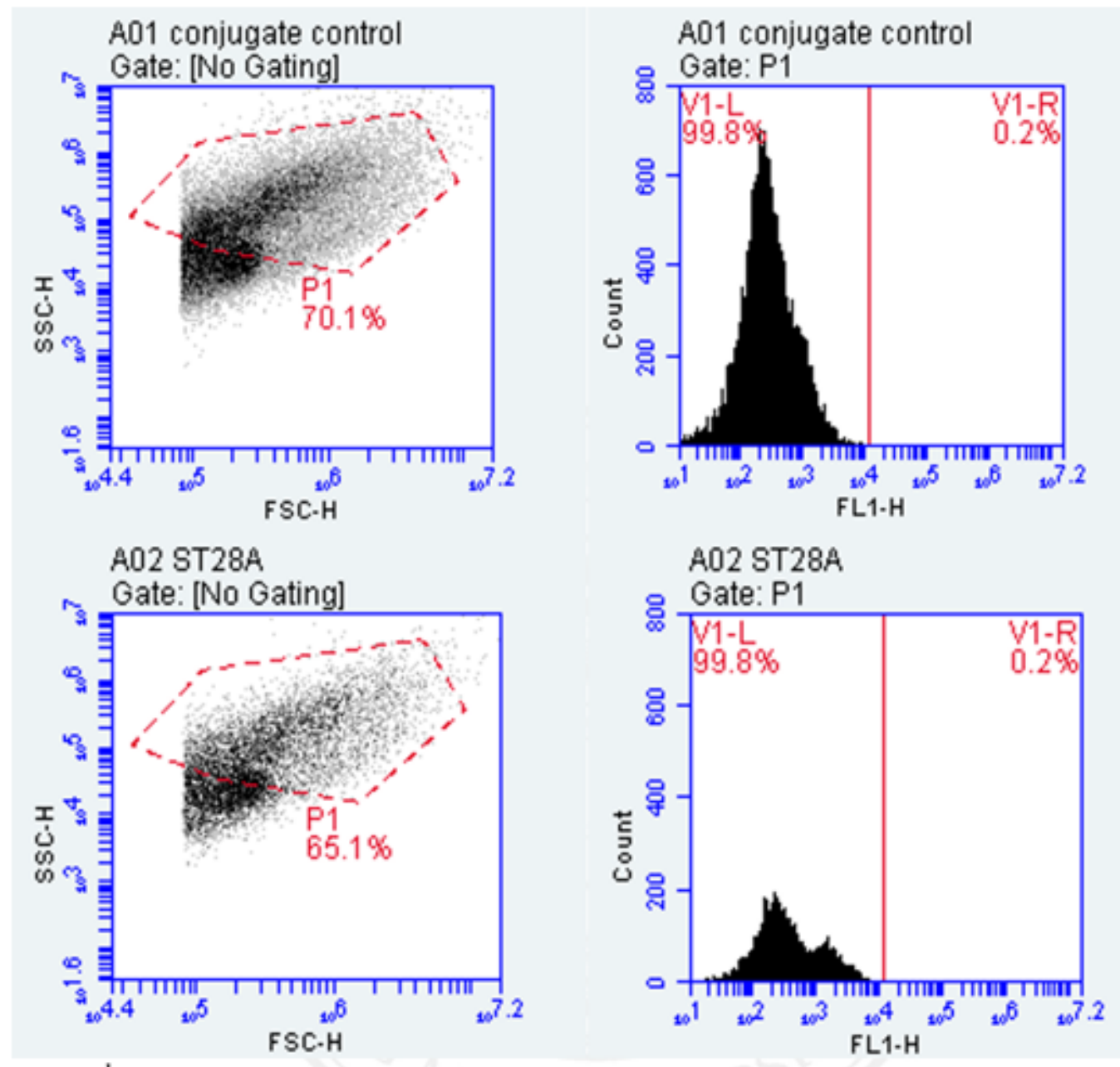

\section{Figure 1}

The physical attributes of the Control sample show the relationship between Forward Scatter Height (FSC-H) and Side Scatter Height (SSC-H) values in Dot Plot format (left) and the relationship between the fluorescence concentration (FL1-H) and the number of cells (Count) in the histogram (right). 

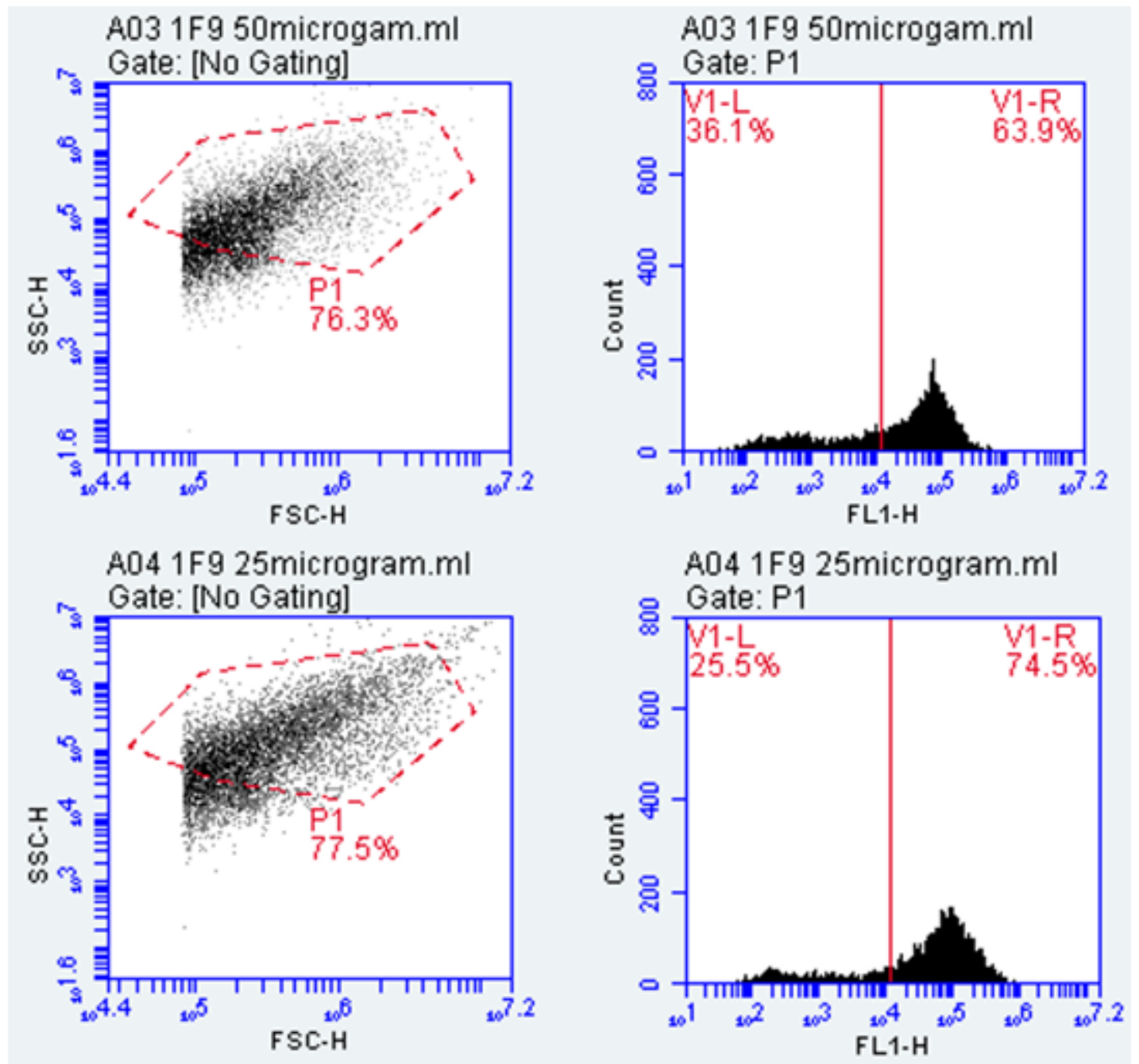

\section{Figure 2}

The relationship between Forward Scatter Height (FSC-H) and Side Scatter Height (SSC-H) in Dot Plot format. $X$ axis or Forward Scatter Height is the cell size indicator. $Y$ axis is a measure of other properties such as Granularity. Probability P1 is an area of a group of sperm cells. Selection of P1 probability areas of 1F9 monoclonal antibody at various concentrations. 


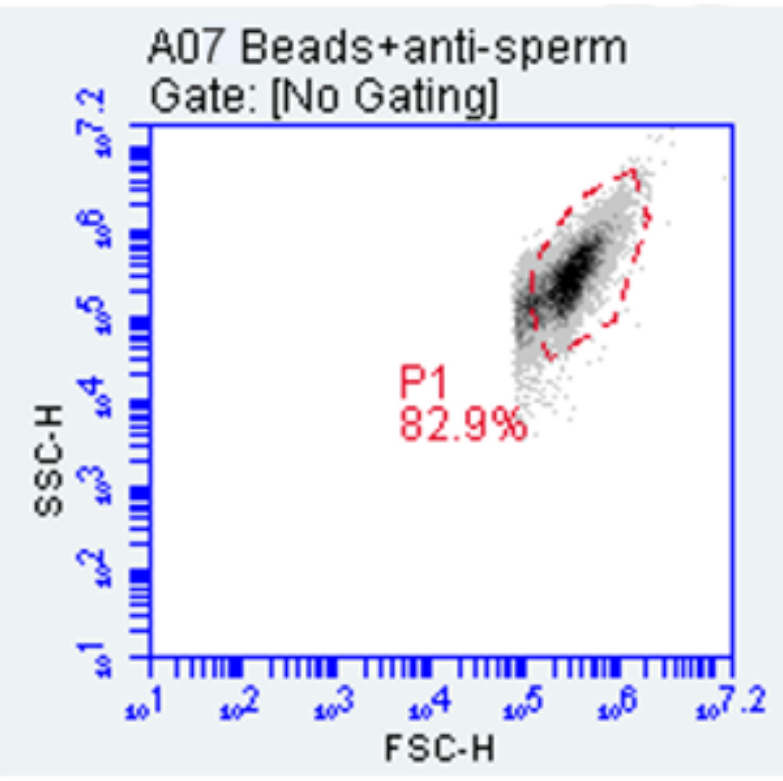

a

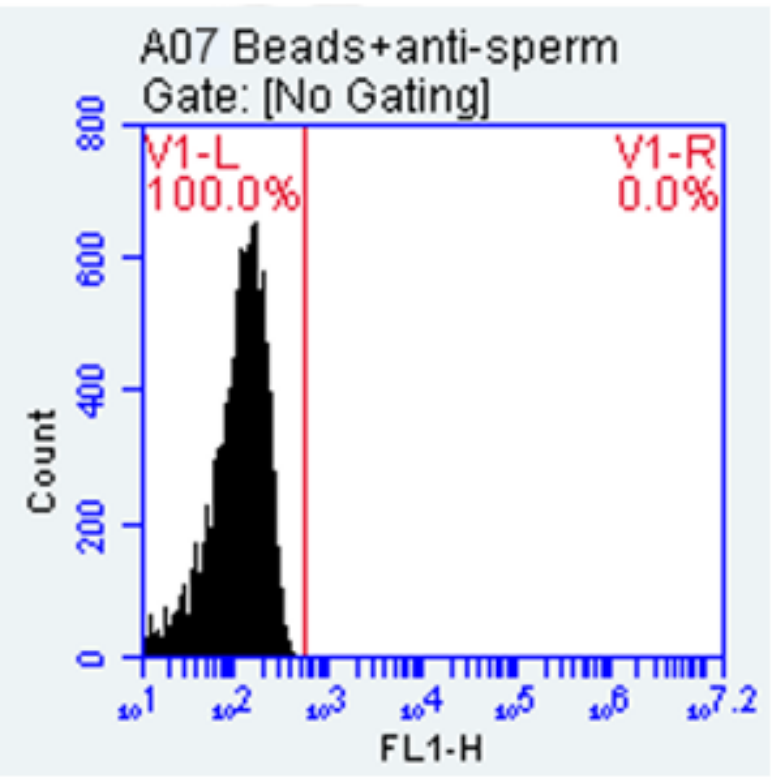

b

\section{Figure 3}

Physical characteristics of magnetic bead on monoclonal antibody 1F9 showing the relationship between Forward Scatter Height (FSC-H) and Side Scatter Height (SSC-H) in the dot plot model (a) and the correlation between the Fluorescent Light Intensity (FL1-H) and the number of cells (Count) in the histogram (b).

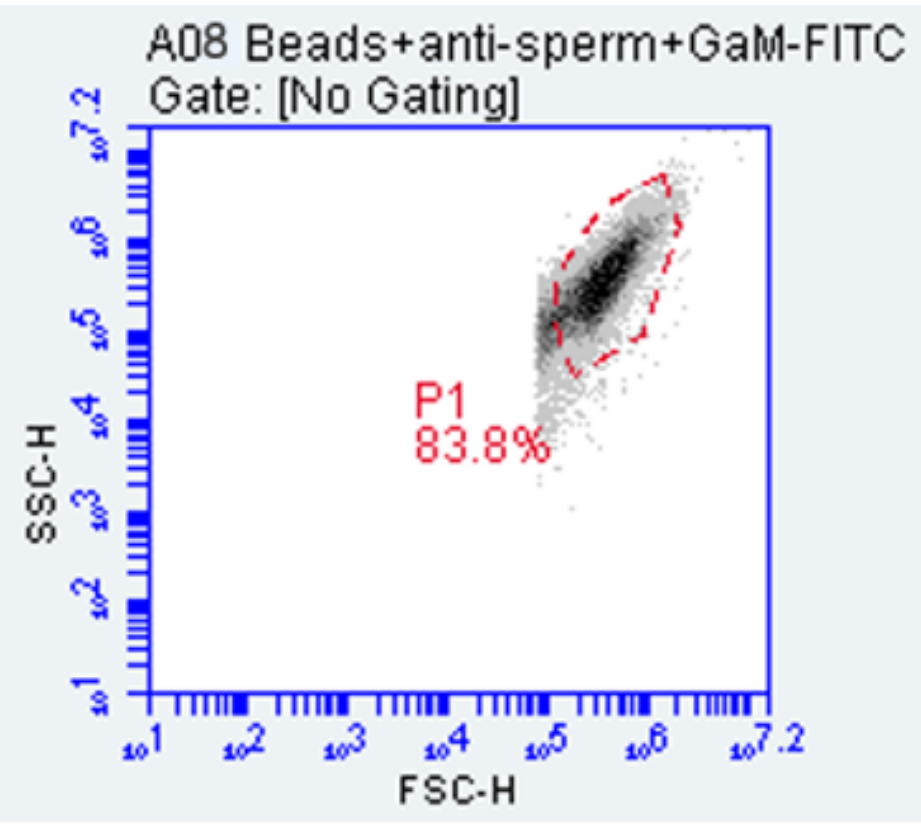

a

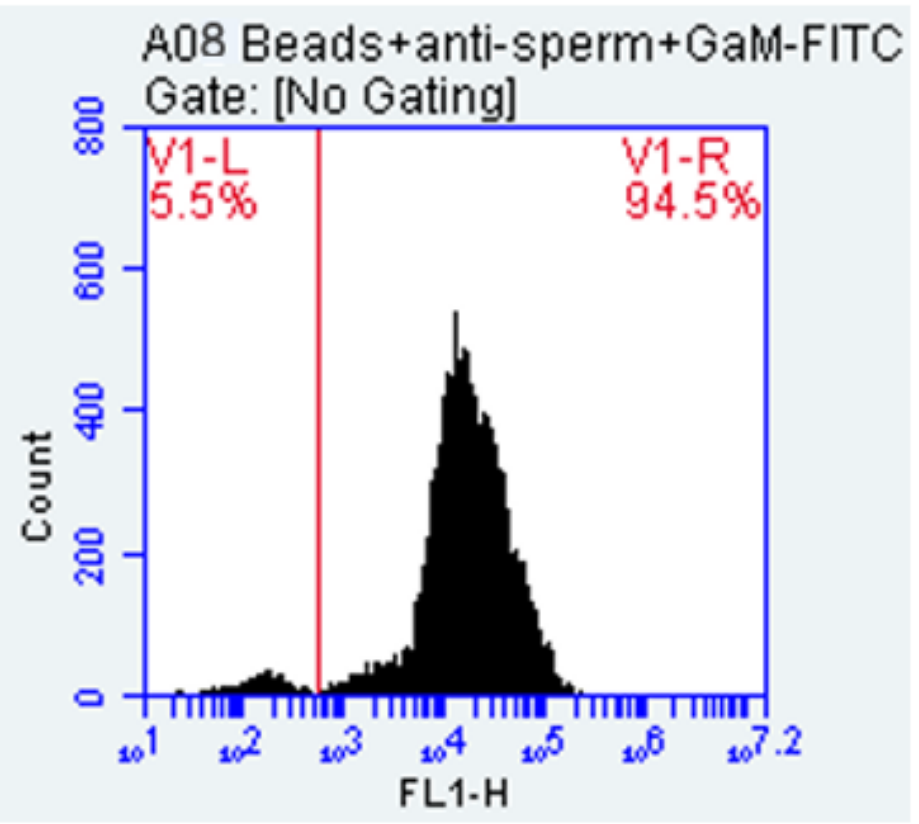

$\mathrm{b}$ 


\section{Figure 4}

Physical characteristics of the Magnetic Bead on Monoclonal Antibody 1F9 stained with GaM-FITC, showing the relationship between Forward Scatter Height (FSC-H) and Side Scatter Height (SSC-H). In the Dot Plot model (a) and the correlation between the Fluorescent Light Intensity (FL1-H) and the number of cells (Count) in the Histogram (b).

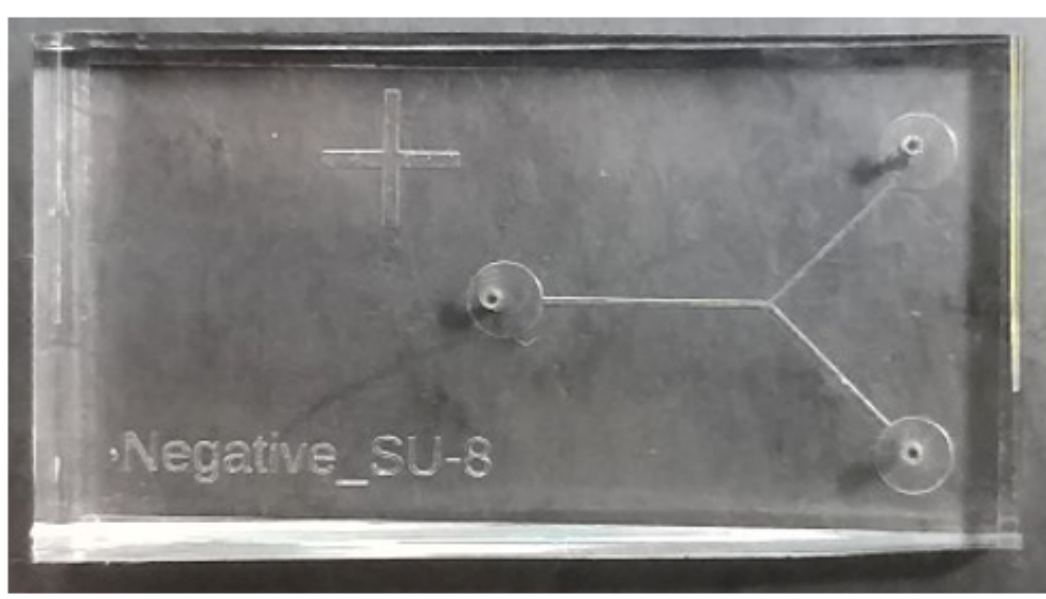

a

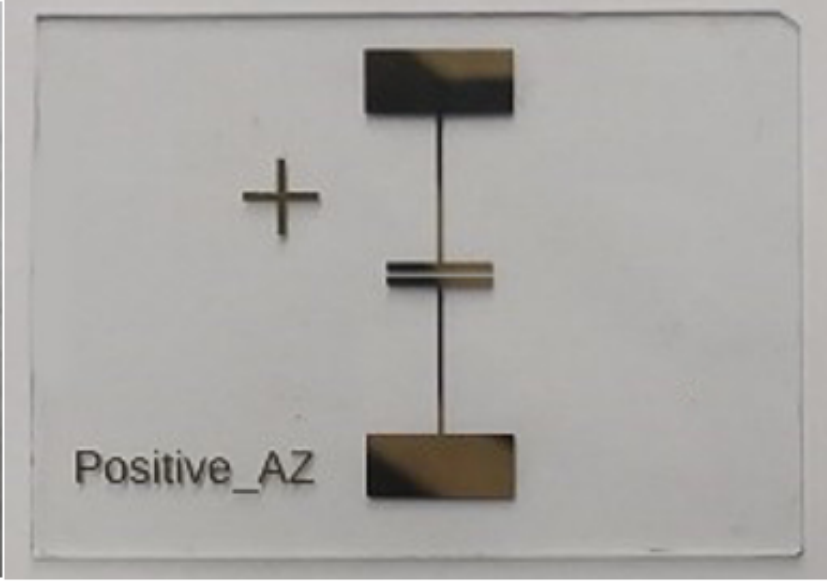

b

\section{Figure 5}

The microfluidic chip fabricated by photolithography. (a) Ti/Au electrodes microchip and (b) $Y$ microchannel for the flow in the microfluidic chip. 


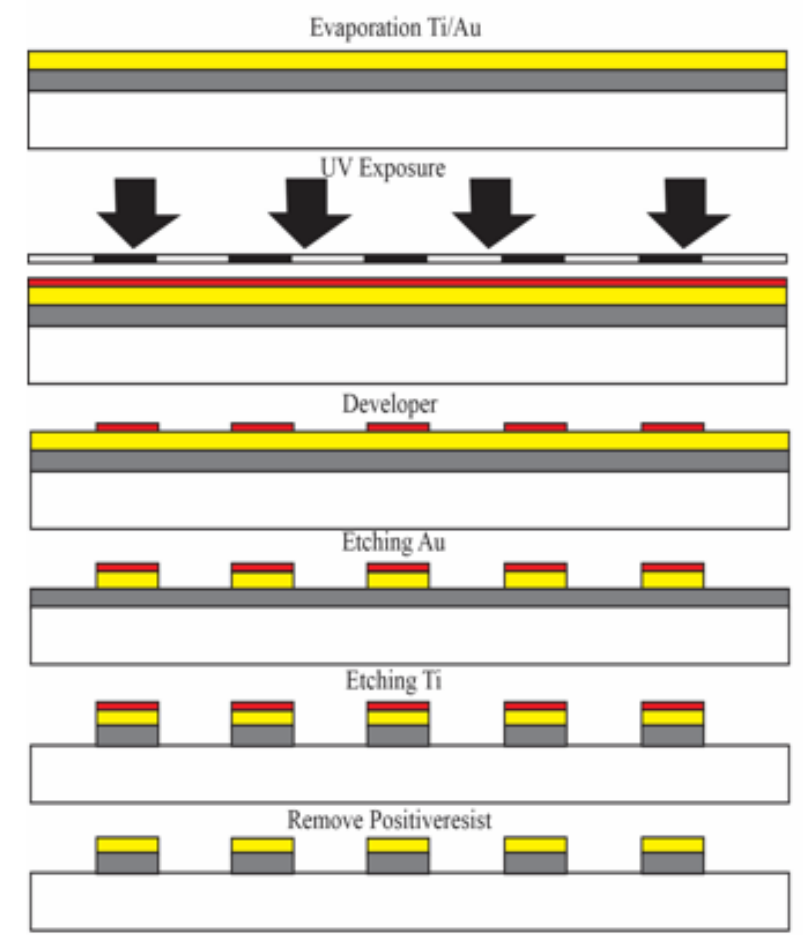

$\square$ Glasss substrate $\square$ Positive photoresist (AZ P1512) $\quad$ U UV Mask $\square \mathrm{Au} \quad \square \mathrm{Ti}$

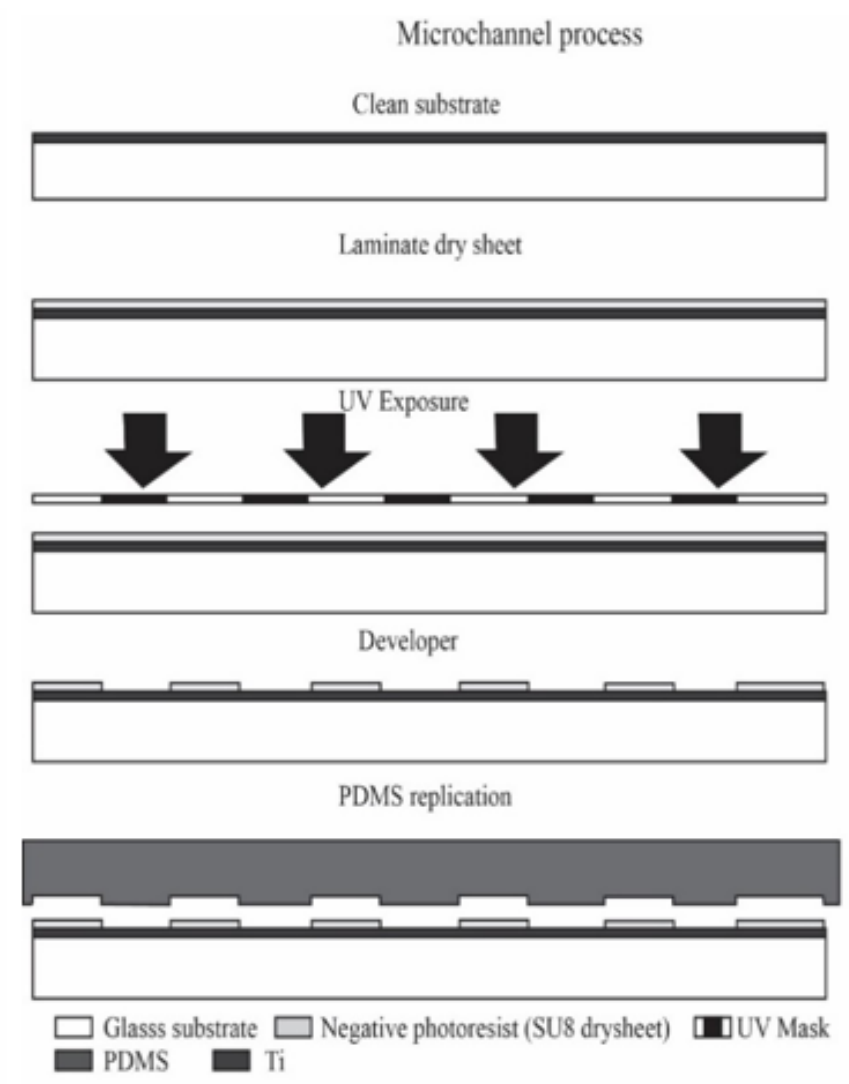

b

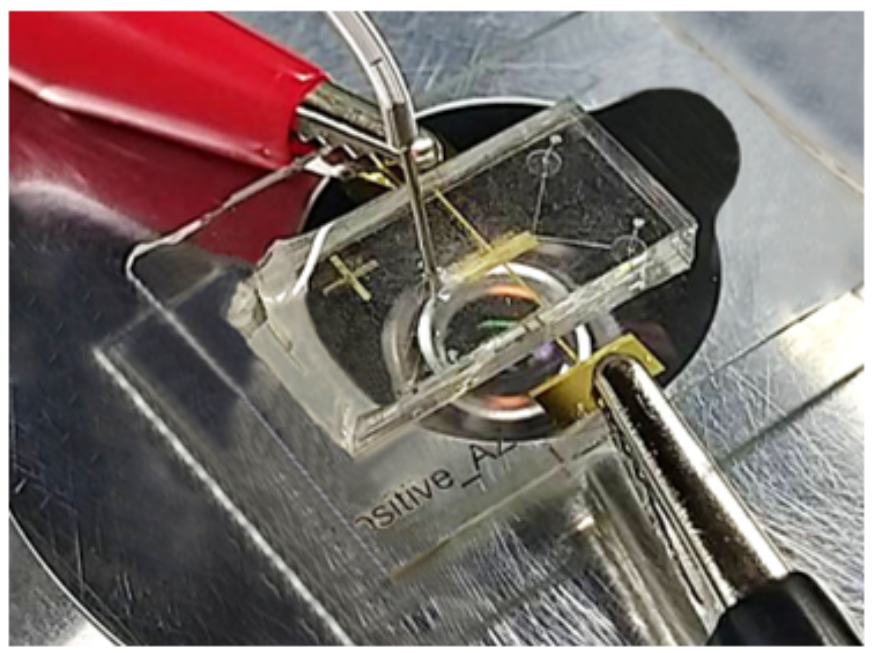

C

\section{Figure 6}

Illustration of the microfluidic device fabrication process using ultraviolet and soft lithography. (a) Fabrication of the microelectrodes and (b) fabrication of the microchannels. 


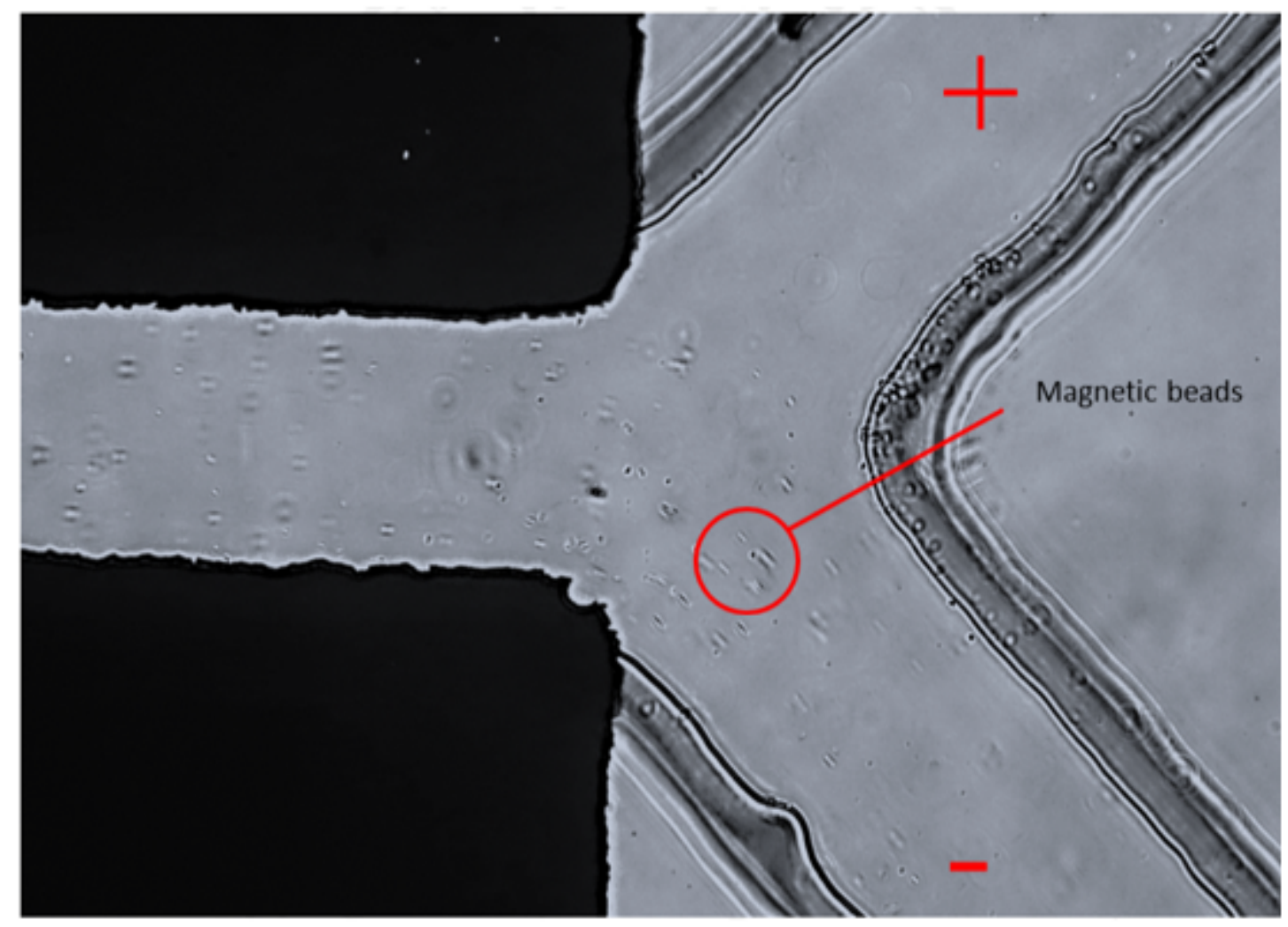

Figure 7

The flow of the magnetic particle in the microstructure flow channel with microfluidic chip.

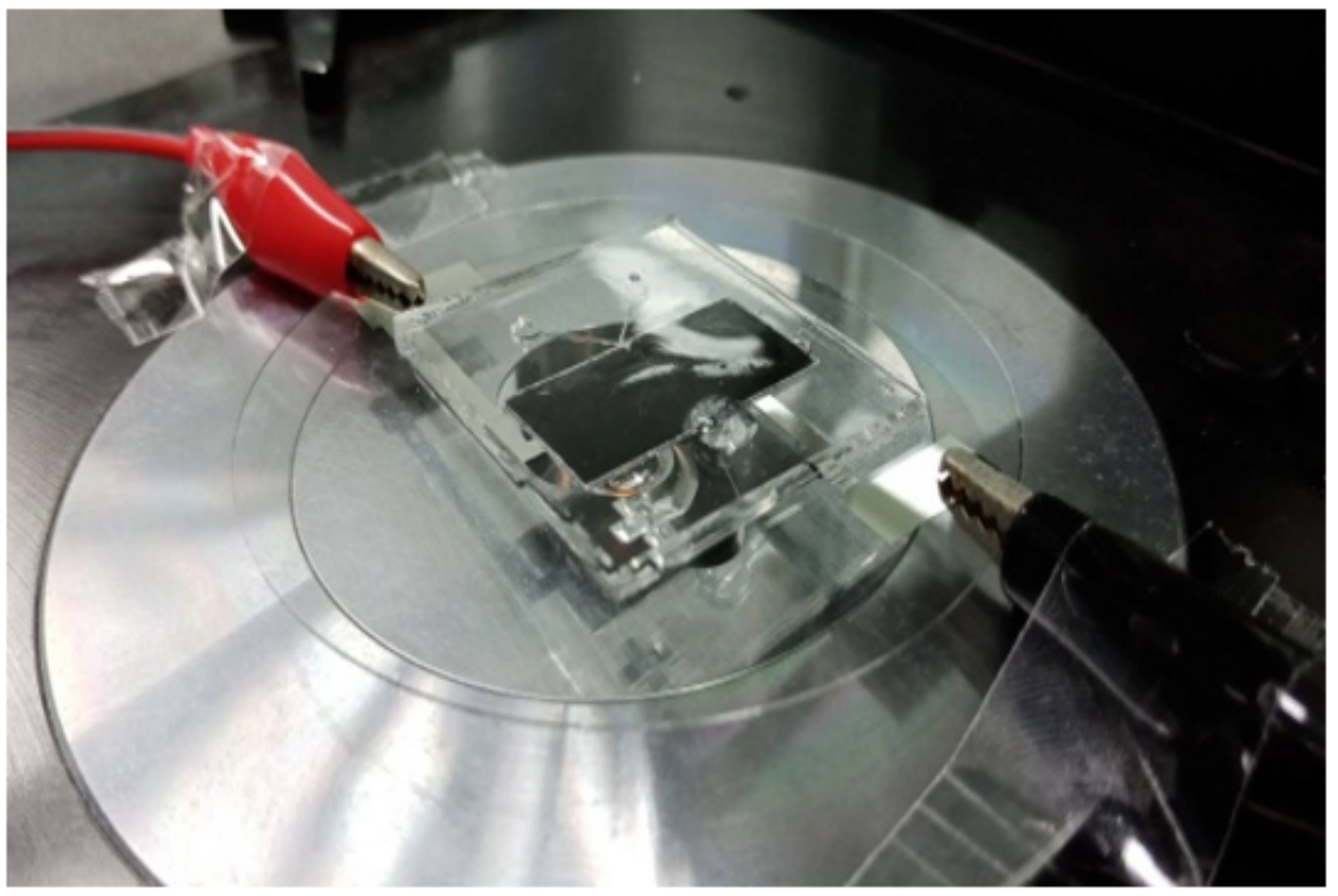

Figure 8 
The structure of MWCNT-microfluidic chip

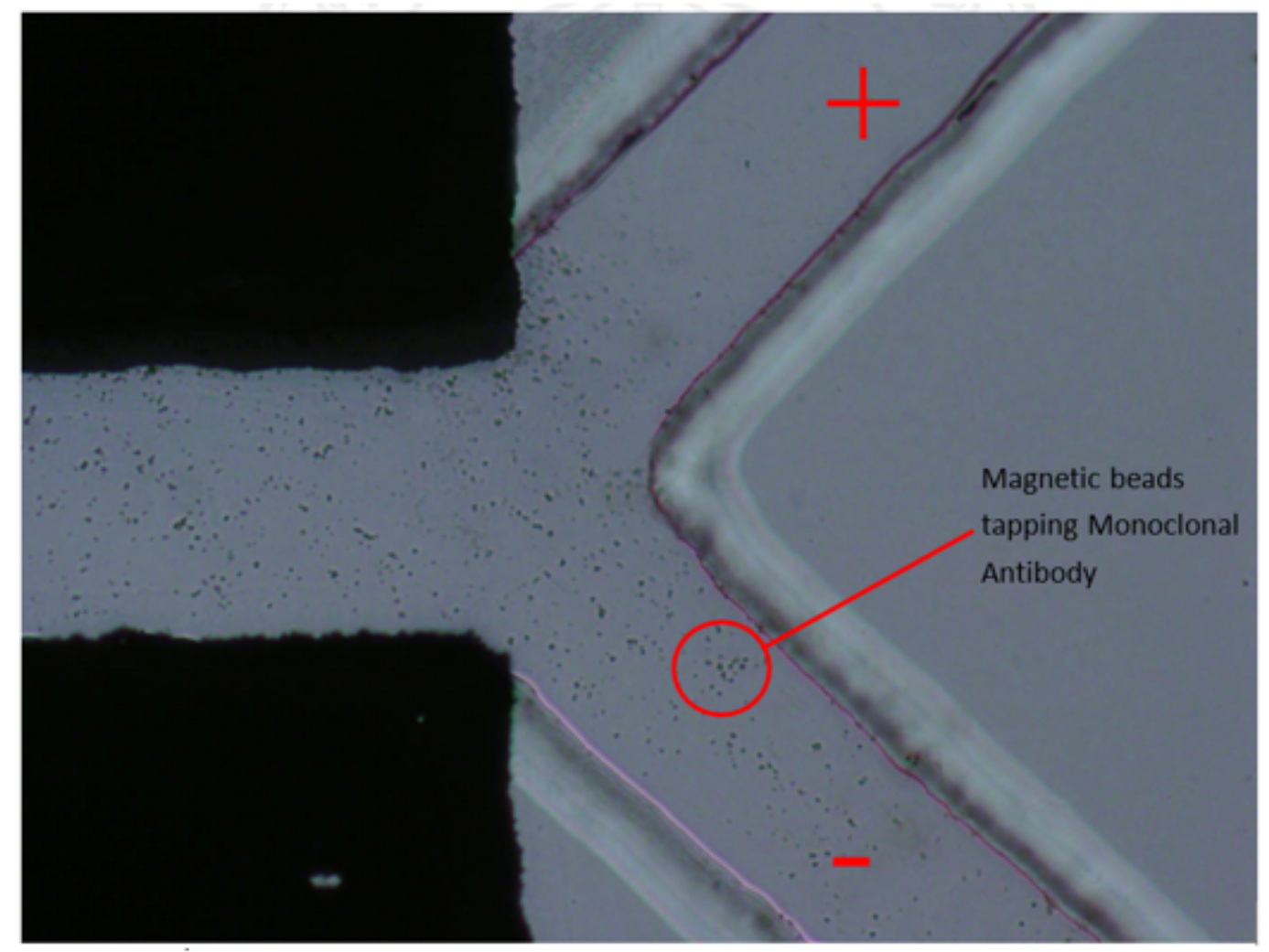

Figure 9

Magnetic particles flow on a monoclonal antibody in microstructure flow channel with microfluidic chip.

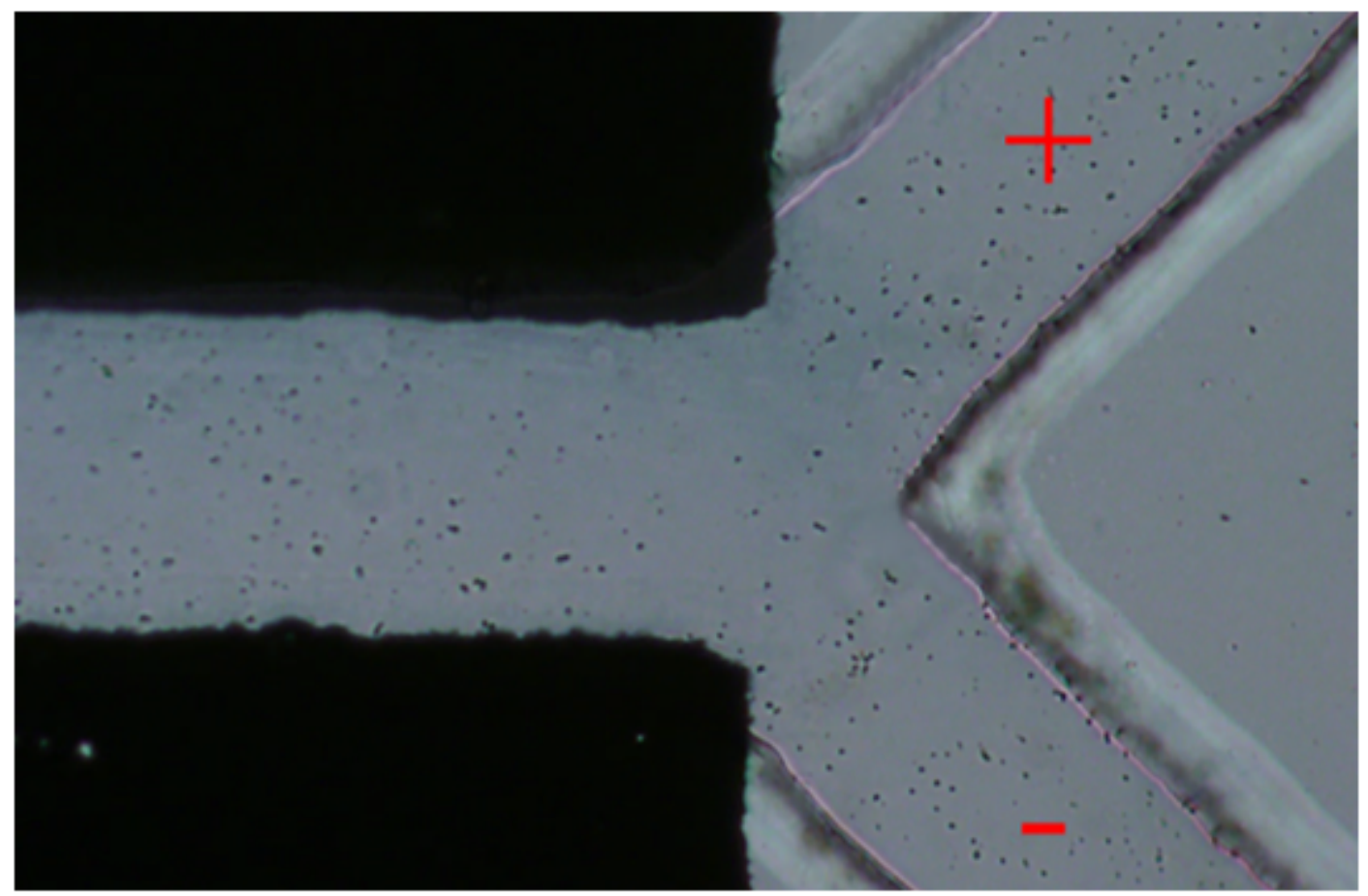

Figure 10 
Flow of the magnetic particles on a monoclonal antibody and sperm in microstructure flow channel with microfluidic chip. 